\title{
GÉNERO, DIVERSIDADE E CIDADANIA
}

\author{
Coordenação \\ Fernanda Henriques
}

\section{Ediçōes Colibri}

CIDEHUS/UE - Centro Interdisciplinar de História, Culturas e Sociedades da Universidade de Évora 
Biblioteca Nacional-Catalogação na Publicação

Género, diversidade e cidadania / coord. Fernanda Henriques. (Biblioteca - estudos \& colóquios; 16)

ISBN 978-972-772-762-9

HENRIQUES, Fernanda, 1946-

CDU 305

Título: Género, Diversidade e Cidadania

Coordenação: Fernanda Henriques

Edição: Ediçōes Colibri/NEHM/CIDEHUS-UE - Centro Interdisciplinar de História, Culturas e Sociedades da Universidade de Évora

Capa: TVM

Depósito legal: 266 178/07

Lisboa, Junho de 2008 


\title{
MANUAIS DE EDUCAÇÃO FÍSICA: EM ROTA DE COLISÃO COM GENERO, DIVERSIDADE E CIDADANIA?
}

\author{
Paula Botelho Gomes" \\ Paula Silva \\ Telma Queirós \\ Silvia Caetano
}

\section{Notas introdutórias}

Em resposta ao convite para participar na publicação Género, Diversidade e Cidadania, organizada pela Universidade de Évora, e face ao tema a versar no presente texto - o papel dos manuais escolares na educaçăo para a diversidade -, orientámos o nosso pensamento pelas seguintes posiçōes:

- desporto é um fenómeno antropológico, social e global, que nos remete para a sua humanidade e para a necessidade de ser "educado" e cuidado, pois ele não tem vida para além da que lhe conferimos. Assim, o desporto convida para distintas possibilidades de motivos e práticas e, também por isso, deve ser factor de civilização e de qualificação da cidadania. Se nos é permitida a ousadia de parafrasear Schiller, 'a humanidade só é verdadeiramente humana quando joga', e daí a importância de jogar e ensinar a jogar;

- educação física é a disciplina que trata pedagogicamente o desporto na escola (o desporto como matéria de ensino); percorre o sistema de educativo do $1 .^{\circ}$ ao $12 .^{\circ}$ ano e, num espaço de 12 anos, tem como objec-

\footnotetext{
${ }^{2}$ Professora Associada da Universidade do Porto-'Faculdade de Desporto. Doutorada em Pedagogia do Desporto. Directora do Curso de Mestrado em Ciência do Desporto. Presidente da Associação Portuguesa Mulheres e Desporto. 'Professora Auxiliar da Universidade do Porto - Faculdade de Desporto. Doutorada em Ciências do Desporto. 'Docente do Instituto Politécnico de Bragança, Escola Superior de Educaçăo. Mestre em Ciências do Desporto. Docente do Ensino Secundário. Mestre em Ciências do Desporto.
}

Género, Diversidade e Cidadania, Lisboa, Ediçōes Colibri/CIDEHUS-UE, 2007, pp. 89-101. 
tivo a formação desportivo-corporal de crianças e jovens sem discriminaçôes de sexo, raça/etnia, classe social ou de capacidade física. "... a educação física e desportiva distingue-se de outras áreas, no concernente à sua tarefa educativa primordial, pelo facto de educar, formar, socializar e possibilitar experiências a partir do corpo" (Bento, 2004, p.29);

- género, enquanto categoria analítica, é entendido como representação simbólica, culturalmente relativa, de masculinidades e de feminilidades e relações de poder entre estas duas categorias;

- diversidade é o que melhor nos caracteriza como indivíduos e sociedade, e, assim, factor de pluralidade, riqueza e de legitimação da diferença.

Conjugar educação, cidadania ${ }^{1}$ e desporto / educação física reporta à relação biunívoca entre direitos e deveres e às ideias de pertença e participação, legítimas e reconhecidas, numa comunidade, neste caso escolar.

No que se refere a manuais escolares, realça-se a sua importância enquanto produtos pedagógicos mediadores do processo de ensino e aprendizagem e na socialização e formação de identidades, e como contributo para a formação cívica e democrática de alunos/alunas (DEB, circ. n. ${ }^{\circ} 7 / 2000$ ).

Arrumadas estas ideias, de forma muito sucinta, voltemo-nos para o tema proposto, examinando as imagens de manuais escolares de educação física (2.० e $3 .^{\circ}$ ciclos do ensino básico), mostrando como inquinam princípios de cidadania e da diversidade, sublinhando-se a necessidade de eliminar estereótipos, pré-conceitos e de se questionar representaçóes sociais de senso comum, 'naturalizadas', neles reproduzidas.

Representaçōes de género, raça/etnia e de alunos/as com necessidades educativas especiais em manuais de educação física do $2 .^{\circ}$ e $30^{\circ}$ ciclos de ensino

Os resultados a apresentar são oriundos ${ }^{2}$ de duas dissertações de mestrado 3 , que tinham como objectivo verificar como sexo/género, raça/etnia e alunos/as com necessidades educativas especiais estavam

1 Em 'cidadania' engloba-se, de forma transversal, as perspectivas de diversidade e género e a necessidade de consciencializaçăo crítica no tocante a estereótipos.

${ }^{2}$ Os dados originais foram simplificados e trabalhados com o objectivo de uniformizar critérios de apresentação de resultados neste colóquio.

${ }^{3}$ Caetano, Sílvia. (2005). Representaçôes de género e de etnia. Estudo realizado em manuais de educaçăa fisica do $3 .^{\circ}$ ciclo do ensino básico. Dissertação de mestrado, Universidade do Porto: FCDEF. Queirós; Telma (2004). [Des] Igualdades de oportunidades nos manuais escolares de educaçăo fisica do $2 .^{\circ}$ ciclo do ensino básico? Análise das ilustra̧̧öes e das percepföes de professores/as estagiários/as. Dissertaçăo de mestrado, Universidade do Porto: FCDEF. 
representados em 9 manuais do $20^{\circ}$ ciclo e em 7 do $30^{\circ}$ ciclo, e como se associavam as matérias de ensino ao género (o que é considerado, pretensamente, do domínio 'masculino' e/ou do 'feminino').

Os manuais foram seleccionados entre os que se encontravam disponíveis no ano lectivo 2003-04 e que detinham as maiores quotas do mercado. No conjunto das duas dissertaçōes foram analisadas mais de 8.000 imagens, recorrendo-se a análise do conteúdo.

Representação masculina, feminina e de ambos os sexos por manual do $2 .^{\circ} \mathrm{e}$ do $3 .^{\circ}$ ciclos do ensino básico

O modelo de escola mista, modelo vigente em Portugal apesar de em muitos documentos oficiais se diga coeducativo, assume a escola como uma instituição neutra, promotora da igualdade de oportunidades $^{4}$, onde alunas e alunos são sujeitos às mesmas matérias de ensino. Seria de esperar uma representação, feminina, masculina ou de ambos os sexos, equilibrada nos exemplos, nas ilustraçôes de que os manuais se socorrem para clarificar pontos importantes da matéria de ensino.

Mas não é bem isso que a leitura dos quadros l e 2 nos mostra:

Quadro 1: Percentagem (\%) de imagens masculinas, femininas e de ambos os sexos por manual do $2 .^{\circ}$ ciclo

\begin{tabular}{|l|c|c|c|c|c|c|c|c|c|}
\hline Sexo/Manual & M1 & M2 & M3 & M4 & M5 & M6 & M7 & M8 & M9 \\
\hline Masc & 60 & 66 & 44.2 & 61.4 & 15.6 & 33.2 & 58.7 & 87.3 & 45.3 \\
\hline Fem & 27 & 20 & 27.5 & 29.3 & 75.9 & 28.2 & 17.1 & 9.7 & 24.3 \\
\hline Ambos & 13 & 14 & 28.3 & 9.3 & 8.5 & 38.6 & 24.2 & 3.0 & 30.4 \\
\hline
\end{tabular}

Nos manuais do $2 .^{\circ}$ ciclo, uma inspecção-geral aos valores encontrados, para cada categoria, permite afirmar que, em 5 dos manuais analisados, as imagens se conjugam fundamentalmente no masculino (M1, M2, M4, M7 e M8, com valores acima dos 58\%). A sobrevalorizaçäo da figura masculina tem como reverso da medalha a invisibilidade feminina.

Uma excepção assinala-se no M5, mas que também evidencia uma representaçáo assimétrica e, como tal, muito pouco compreensível e, pedagogicamente, não recomendável: o elevadíssimo protagonismo iconográfico do sexo feminino.

Em ambos os casos não se vislumbra uma hipótese explicativa para tal ostracismo, que é mais flagrante para as raparigas; este tipo de mensagem não deixa muito espaço para dúvidas: as coisas do desporto, mesmo a nível escolar, não serão muito apropriadas a raparigas, ou que as alunas

\footnotetext{
${ }^{4} \mathrm{Em}$ nosso entender, e de outras autoras, a igualdade de oportunidades resume-se a uma efectiva igualdade de acesso (conf. Botelho Gomes; Silva; Queirós, 2000).
} 
não servem de modelo nas tarefas motoras. Este défice de reconhecimento feminino nos manuais de educação física não permite que as raparigas neles se revejam ou se identifiquem. É ainda um exemplo de sexismo, e não serve a educação na/para a cidadania.

Os resultados levam-nos a considerar o M6 como um manual equilibrado, face à distribuição das imagens pelas categorias em análise (imagens masculinas, femininas e de ambos os sexos).

Os valores registados para a categoria ambos, em M5, M4, M1, M2 e M8 (caso extremo de 'mau exemplo'), indiciam que as matérias da educação física não se prestam a situaçōes de trabalho em grupo ou em par mistos; facto estranho numa matéria de ensino ministrada, num mesmo tempo e espaço, a rapazes e raparigas e onde, em muitas circunstâncias, o trabalho individual não é compatível com a aprendizagem dessas mesmas matérias. Assim sendo, seria de esperar que a categoria ambos estivesse melhor representada.

No que se refere à análise dos resultados para os manuais do $3 .{ }^{\circ}$ ciclo, observamos que as imagens masculinas são sempre percentualmente superiores às femininas e que em cinco deles (M1, M3, M5; M6 e M7) os valores são superiores a $50.0 \%$. Portanto, as críticas tecidas para os manuais do $2 .^{\circ}$ ciclo aplicam-se aqui do mesmo modo.

Quadro 2: Percentagem (\%) de imagens mascilinas, femininas e de ambos os sexos por manual do $3 .^{\circ}$ ciclo

\begin{tabular}{|l|l|l|l|l|l|l|l|}
\hline Sexo/Manual & \multicolumn{1}{|c|}{ M1 } & \multicolumn{1}{c|}{ M2 } & \multicolumn{1}{c|}{ M3 } & \multicolumn{1}{c|}{ M4 } & \multicolumn{1}{c|}{ M5 } & \multicolumn{1}{c|}{ M6 } & \multicolumn{1}{c|}{ M7 } \\
\hline Masc & 67.4 & 43.2 & 74.0 & 47.3 & 50.2 & 93.9 & 55.7 \\
\hline Fem & 21.9 & 40.4 & 21.6 & 28.4 & 26.6 & 5.7 & 32.0 \\
\hline Ambos & 10.7 & 16.4 & 4.4 & 24.3 & 23.2 & 0.4 & 12.3 \\
\hline
\end{tabular}

Aluno e alunas transitam de ciclo de ensino, mas as estereotipias e invisibilidades mantêm-se e assim se reforçam e consolidam. Os manuais de educação física dão razão àqueles/as que se referem a educação física como um local de construção da masculinidade hegemónica (Clarke; Gill, 2001; Silva, 2005).

Mesmo considerando os manuais em análise como exemplos de assimetria e enviesamento na representação de alunas e de alunos, não podemos deixar passar em claro o caso desconcertante do manual M6: a elevadíssima representação masculina leva a pensar que o manual reflecte um curriculum segregado, e que o autor ou a autora, de longe a longe, 'compõe', 'anima' o quadro incorporando a figura feminina.

Lamentavelmente, os manuais dos dois ciclos de ensino, para as três categorias representadas, revelam uma concepção genderizada da educação física, a força das crenças e do currículo oculto dos autores/as e a dis- 
criminação directa das alunas, ainda que, provavelmente, não seja fruto de um acto consciente ou propositado. Por isso, em análises subsequentes, o termo sexo deve ser substituído pelo termo género.

Associação do género às matérias de ensino nos manuais do $20^{\circ} \mathrm{e} 30^{\circ}$ ciclos de ensino

O assinalado anteriormente como que anuncia que nem todos os conteúdos programáticos são tidos como convenientes a raparigas e rapazes. Se, por um lado, a leitura dos quadros 3 e 4 sustenta a suspeição, por outro, reforça uma visão preconceituosa e androcêntrica da educação física.

Quadro 3: Percentagem (\%) de imagens masculinas, femininas e de ambos os géneros associadas às matérias de ensino nos manuais do $2 .^{\circ}$ ciclo

\begin{tabular}{|l|c|c|c|}
\hline Matéria Ensino & Masc & Fem & Ambos \\
\hline Andebol & 73 & 10 & 17 \\
\hline Basquetebol & 72 & 12 & 16 \\
\hline Futebol & 75 & 9 & 16 \\
\hline Voleibol & 58 & 24 & 18 \\
\hline Atletismo & 66 & 24 & 10 \\
\hline Badm+Ténis Mesa & 44 & 24 & 32 \\
\hline Ginástica(s) & 64 & 31 & 5 \\
\hline Nataçäo & 51 & 28 & 21 \\
\hline D. Combate & 54 & 12 & 34 \\
\hline Expl. Natureza & 68 & 16 & 16 \\
\hline Act. Rítmicas & 16 & 65 & 19 \\
\hline Patinagem & 52 & 32 & 16 \\
\hline Corpo Humano & 75 & 12.5 & 12.5 \\
\hline
\end{tabular}

No conjunto dos manuais do $2 .^{\circ}$ e $31^{\circ}$ ciclo em análise os conteúdos estão associados prioritariamente ao género masculino. A única excepção vai para as actividades rítmicas, consideradas culturalmente como do foro feminino, e, como tal, não compatível com a masculinidade.

É certo que, no $20^{\circ}$ ciclo, a(s) ginástica(s) é mais retratada por rapazes do que por raparigas o que parece um tanto ou quanto estranho, tendo em conta os preconceitos que se conhecem. Mas há uma explicação: a ginástica rítmica é apenas um dos componentes da(s) ginástica(s). Outras 'ginásticas' serão consideradas mais compatíveis com a educação dos rapazes.

Interessante é verificar que o voleibol se declina mais masculino do que feminino, contrariando a opinião de alunas e alunos, que o têm como apropriado a ambos (Ferraz, 2002; Silva, Botelho Gomes e Queirós, 2004).

$O$ atletismo português tem uma história importante escrita no feminino. Pois bem, nem no atletismo se verifica um equilíbrio de imagens masculinas e femininas. 
Apesar da quase correspondência de matérias nos dois ciclos de ensino, nos manuais do $3 .^{\circ}$ ciclo constam duas matérias novas: o râguebi e o golfe. A primeira é associada exclusivamente aos rapazes, como se não existissem raparigas e equipas femininas no râguebi; mas entende-se se tivermos em conta a história hipermasculinizada daquele desporto, considerado como uma verdadeira escola de homens, plena de rituais machistas, sexistas e brejeiros (Thompson, 1994; Wheatley, 1994). A segunda, o golfe, é tida fundamentalmente como uma actividade feminina ( $75 \%$ das imagens); neste caso não somos capazes de avançar com nenhuma hipótese de interpretação minimamente plausível.

De assinalar que, até mesmo em duas unidades temáticas onde se abordam conceitos, questões, referentes à saúde, à cultura desportiva, etc., Corpo Humano e Educação Desportiva, os modelos são maioritariamente masculinos.

Quadro 4: Percentagem (\%) de imagens masculinas, femininas e de ambos os géneros associadas às matérias de ensino nos manuais do $30^{\circ}$ ciclo

\begin{tabular}{|l|c|c|c|}
\hline Matéria Ensino & Masc & Fem & Ambos \\
\hline Andebol & 87 & 7 & 6 \\
\hline Basquetebol & 80 & 9 & 11 \\
\hline Futebol & 89 & 6 & 5 \\
\hline Râguebi & 100 & 0 & 0 \\
\hline Voleibol & 61 & 25 & 14 \\
\hline Atletismo & 76 & 19 & 5 \\
\hline Badminton & 84 & 13 & 3 \\
\hline Ginástica & 32 & 51 & 17 \\
\hline Golfe & 21 & 75 & 4 \\
\hline Natação & 48 & 52 & 0 \\
\hline D. Combate & 73 & 4 & 23 \\
\hline Exp. Natureza & 61 & 24 & 15 \\
\hline Act. Rítmicas & 19 & 43 & 38 \\
\hline Patinagem & 57 & 32 & 11 \\
\hline Ed. Desportiva & 65 & 20 & 15 \\
\hline
\end{tabular}

Como se justifica a perpetuação de distorçōes sexistas em materiais pedagógicos? Quem selecciona as imagens dos manuais e com que critérios?

Como é que docentes 'aprovam' manuais desprezando, negligenciando, critérios de qualidade recomendados pelo Ministério da Educação?

Neste mesmo tipo de análise, quando se comparam os valores percentuais, registados para as categorias ambos, feminina, e masculina, verificam-se duas convergências, a saber: a categoria ambos os géneros é 
superior à feminina para o andebol, basquetebol e desportos de combate, e superior à masculina nas actividades rítmicas. O que quererá isto dizer? Em actividades consideradas menos 'apropriadas' a raparigas ou a rapazes, e assim uma das categorias estar menos representada, a categoria ambos tenta equilibrar a falta de representação associada às matérias de ensino? Não nos parece; parece ser mais por mero acaso do que revelador de uma intenção de inclusão. Note-se que no futebol o mesmo não ocorre, e o futebol seria um bom exemplo.

No conjunto dos manuais analisados, unicamente se verifica um caso onde a representação feminina e a masculina são equilibradas: na natação, no conjunto de imagens dedicadas àquele conteúdo nos manuais do $30^{\circ}$ ciclo. Poder-se-ia dizer que a natação é 'pacífica': foi considerada muito cedo, na história do desporto, como uma actividade apropriada às mulheres. Como é óbvio, este tipo de argumentação é inválido para os manuais do $2 .^{\circ}$ ciclo, caindo assim por terra.

Os resultados verificados veiculam nos jovens e na comunidade escolar modelos estereotipados de educação física/desporto, 'masculinizando' ou 'feminizando' as práticas, podendo não só levar a comportamentos homofóbicos (Silva, Botelho Gomes e Queirós, 2004), como a condicionar, experiências, vivências e conhecimentos culturalmente interessantes para formaçáo desportivo-corporal de rapazes e raparigas.

Socorrendo-nos de Sílvia Roque (2004), diríamos que a questão das representaçóes" nos manuais escolares se trata do não visto ou da visibilidade formatada.

Ora, registo visual traz: sempre implícito um certo grau de interpretação do facto representado (Calado, 1994), e as imagens não são neutras: ajudam a modelar o universo mental (Lima e Chaves, 2001).

Representaçōes raça/etnia ( $R, E)$ e de alunos/as com necessidades educativas especiais (NEE) por manual do $2 .^{\circ}$ e $3 .^{\circ}$ ciclos do ensino básico

Como se pode observar nos quadros 5 e 6 , no tocante à representaçáo de alunos/as de diferentes raças/etnias, e num exercício de ironia da nossa parte, dir-se-ia que Portugal não é um país de imigrantes e minorias étnicas; ou, então, essas populações pouco frequentarão a escola, ou não servirão como chamada de atençáo para o facto de no espaço da escola portuguesa coexistirem, em graus variáveis, alunos/as de diversas raças/etnias. Se o manual M8 ignora a situação por completo, o M9 poderá ser um bom exemplo de inclusão.

O trabalho relativo ao $2 .^{\circ}$ ciclo foi muito feliz na decisão de averiguar se as imagens incluíam representaçōes mistas (mais que uma raça/etnia numa mesma imagem). Pelos valores registados, em seis manuais, parece ter havido esse propósito. 
Quadro 5: Percentagem (\%) de imagens relativas à raça/etnia (R,E) por manual do $20^{\circ}$ ciclo

\begin{tabular}{|l|c|c|c|c|c|c|c|c|c|}
\hline R,E/Manual & M1 & M2 & M3 & M4 & M5 & M6 & M7 & M8 & M9 \\
\hline Caucasiana & 87.7 & 97.5 & 88.2 & 80.2 & 96.0 & 91.7 & 91.7 & 100 & 69.7 \\
\hline Mistas & 10.7 & 1.1 & 10.8 & 7.9 & 2.0 & 6.9 & 6.5 & 0.0 & 11.7 \\
\hline Negróide & 0.0 & 0.0 & 0.5 & 11.9 & 2.0 & 0.5 & 1.2 & 0.0 & 18.6 \\
\hline Outras & 1.6 & 1.4 & 0.5 & 0.0 & 0.0 & 0.9 & 0.6 & 0.0 & 0.0 \\
\hline
\end{tabular}

Os manuais do $2 .^{\circ}$ e $3 .^{\circ}$ ciclos, no que concerne à categoria outras, não nos chamam à atenção para a diversidade rácica/étnica que convive nas aulas e nos recreios de muitas escolas, e no país, conforme expressa a figura 1.

Quadro 6: Percentagem (\%) de imagens relativas à raça/etnia (R,E) por manual do $3 .^{\circ}$ ciclo

\begin{tabular}{|l|c|c|c|c|c|c|c|}
\hline R,E / Manual & M1 & M2 & M3 & M4 & M5 & M6 & M7 \\
\hline Caucasiana & 94.5 & 98.3 & 89.5 & 86.3 & 97.5 & 92.5 & 95.2 \\
\hline Negróide & 5.0 & 1.7 & 10.3 & 0.7 & 2.5 & 6.6 & 2.0 \\
\hline Outras & 0.5 & 0.0 & 0.2 & 13.0 & 0.0 & 0.9 & 3.0 \\
\hline
\end{tabular}

Figura $1^{*}:$ Percentagem de alunos matriculados no ensino não superior segundo grupo cultural /nacionalidades distintas da maioritária. e sua distribuição por níveis de ensino (\%) - Portugal 1999/02.
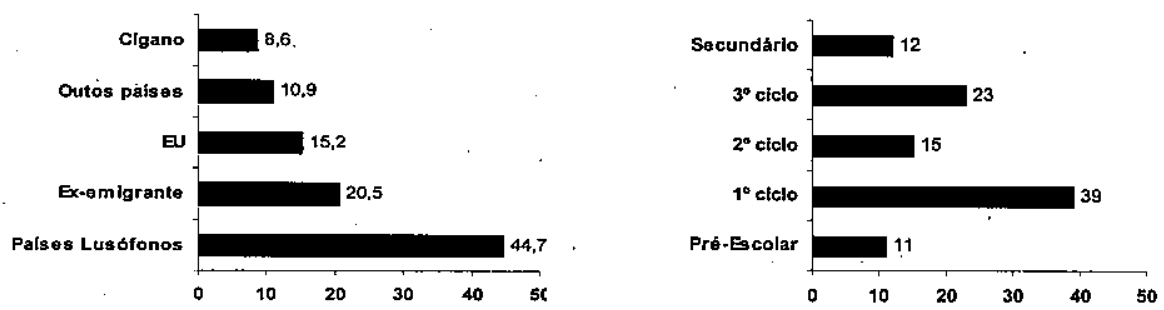

*Adaptado de Marques e Martins (2005, pp. 41, 42).

Os resultados apresentados nos quadros 5 e 6 , se confrontados com os da figura 1, falam por si.

Atente-se aos comentários de Marques e Martins (2005, pp. 6 e 8): 
Em simultaneidade, como se dá conta no presente estudo, já cerca de $6 \%$ da população discente nas escolas dos ensinos básico e secundário é constituída por estudantes não autóctones (dados de 1999/2000). A forte aceleração dos fenómenos migratórios verificada nos últimos cinco anos levar-nos-ia a pensar que essa percentagem deverá, entretanto, ter-se alterado para cima.

$\mathrm{Na}$ realidade, se nos fosse pedida uma inferência estratégica do estudo, com inequívoca implicação ao nível do desenho da política pública, destacaríamos a proverbial dificuldade da escola portuguesa em discriminar positivamente, no sentido de atenuar factores contextuais de exclusão socio-cultural que à escola compete combater sem descanso.

E acrescentamos: os manuais perdem a oportunidade de pôr em evidência o desporto como conteúdo e linguagem universais. Duas características que facilitam o encontro de culturas, a consideração pelos outros.

A "diversidade ensina"; "A educação pela diversidade vale-se das potencialidades oferecidas pela diversidade" (Junqueira, 2007, p. 59), criando um sentido de pertença e dando o direito de ser diferente.

Preocupaçōes com alunos e alunas com necessidades educativas especiais também estavam na mira das dissertaçốes aqui revisitadas.

Em nenhum dos manuais trabalhados foram encontradas referências, seja de que tipo for, a esta categoria de alunos/as.

Inclusão é, também, educação de alunos e alunas com necessidades educativas especiais. Inclusão é uma consciência de comunidade, uma aceitação das diferenças, uma co-responsabilização para obviar às necessidades de outros (Stainback e Stainback, 2001).

As diferenças não se podem converter em desigualdades.

Rapazes e raparigas, com necessidades educativas especiais, devem usufruir das ạulas de educação física, através de tarefas ajustadas às suas capacidades e competências. No entanto, os 16 manuais analisados não dấo conta deles, delas... Como se não existissem na escola. Como se não existissem para o desporto. Como se o desporto não fosse um valor e um direito. Como que ignorando os Jogos Paralímpicos, onde portugueses e portuguesas sistematicamente arrecadam medalhas sobre medalhas.

Os autores e autoras dos manuais, profissionais de educação física, tendo frequentado cursos superiores com disciplinas que versam esta temática, e com colegas com cursos de especialização em desporto adaptado, a quem poderiam pedir colaboração, na hora de conceberem um manual, o modelo que têm em mente é o masculino, à boa maneira do Barão Pierre de Coubertin, e sem 'mácula', de nascença ou decorrente de acidentes.

Se às raparigas thes concedem pouco espaço e estereotipado, aos portadores de deficiência / NEE esse espaço permanece em branco. 
Não se está a sugerir que, para cada situação ou tarefa de aprendizagem, se assinale tantas alternativas quanto as possíveis situaçóes especiais eventualmente a encontrar. O que se pretende sublinhar é que tarefas adaptadas; e respectivas imagens de alunos/as com necessidades educativas especiais, e desportos adaptados devem ser contemplados nos manuais. Todos/as beneficiariam, independentemente das suas capacidades, se aprendessem a jogar boccia, goal-ball, futebol, voleibol sentado, etc.

Ou seja, cultura desportiva e educação inclusiva, na diversidade e cidadania.

Importância dos manuais, discriminação, linguagem, mensagem das imagens, adopção de manuais... O que pensam professores e professoras?

Para finalizar, transcrevemos algumas opiniōes de professores e professoras, recolhidas no âmbito dos trabalhos que serviram de suporte a este texto, sem tecer comentário ou tentativa de interpretaçăa:

"Sim acho muito importante (o manual). .... Porque eles têm que acompanhar a matéria a partir dali".

"A maioria dos alunos não compra o manual escolar".

"Pelos trabalhos que entregam tenho conhecimento que utilizam o manual".

"(...) as imagens masculinas são as mais evidentes e as mais numerosas".

“(...) eu penso que não é por nas ilustrações aparecer um menino ou uma menina que náo vai haver igualdade: $O$ importante para mim numa ilustração é ver, digamos, os critérios de êxito de um exercício. Agora, tem um menino ou uma menina acho que não tem diferença nenhuma."

"Talvez porque normalmente o sexo masculino... é o mais forte".

"(...) na actividade do futebol vai encontrar só miudinhos nąs imagens nas ilustraçóes, e na ginástica vai encontrar só meninas a maior parte. Por isso acho que não estão sensibilizados e estão a contribuir para a discriminaçăo".

"(...) há sempre a tendência em ligar a ginástica e a natação ao feminino". (...) do que propriamente desportos colectivos (...)".

"Aparecem alguns negros nalgumas imagens mas não vemos asiáticos, não vemos indianos..."

"Os desenhos... aparecem pessoas praticamente brancas. A maioria rapazes. Não nos demonstra mesmo grupos com pessoas de cor, diferentes, gordas, magras."

"Pelo menos na minha turma tenho, tenho, uma rapariga de etnia 
cigana que é muito bem aceite..., mas tenho um rapaz deficiente que já não é nada aceite nem...".

"Houve livros que já me chegaram até hoje e nenhum deles faz referência sequer a qualquer tipo de deficiências motoras (...), não há nenhuma chamada de atenção nem nos manuais dirigidos para alunos nem nos manuais dirigidos para os professores".

"Eu acho que não era muito necessário estar a separar (declinação da linguagem no feminino e no masculino). (...) Seria estar a gastar mais tinta e papel..."

"(...) mas isso é normal. Basta ver o conceito do Homem, não é? Abarca os dois sexos".

" $\mathrm{E}$ eu sinceramente também nunca reparei, se a linguagem 'tá' mais para o masculino do que para o feminino. Nunca dei muita atenção a estes aspectos".

"Fiz várias (acções de formação) relacionadas com necessidades educativas especiais. Com etnias e género não fiz nenhuma".

"(...) nem se vê acções de formação sobre igualdade de oportunidades."

\section{Conclusôes}

No âmbito do presente trabalho, é possivel concluir que:

- se observa uma forte e consistente associação da educação física ao mundo masculino, expressa pela hipervalorização do modelo masculino e sub-representação da figura feminina nos manuais, e pela acentuadíssima associação de maior parte dos conteúdos aos rapazes. Os manuais transmitem, e assim perpetuam, estereótipos de género;

- as imagens representam quase que exclusivamente caucasianos/as e ignoram alunos/as com necessidades educativas especiais. Assim, não revelam a atenção devida à diversidade de populações.

Istọ é: os manuais não contribuem para a alteração da narrativa hegemónica do desporto (apesar do mundo real a desmentir): 'varōes', 'brancos' e 'perfeitos', contrariando uma educação na cidadania, a socialização de rapazes e raparigas em contexto escolar e a formação desportivo-corporal de todos e de todas.

\section{Recomendaçóes}

O exposto ao longo destas páginas, comprova a necessidade da introdução destas temáticas e preocupaçōes na formação inicial e contí- 
nua de profissionais do desporto, também autores/as dos produtos pedagógicos. Até porque muitas das distorçōes detectadas parecem ser, não só fruto de estereotipias, como também do acaso, da falta de cuidado ou critério pedagógico na escolha das imagens.

Os editores deveriam ser também sensibilizados para os vários itens de qualidade de um manual, de modo a tê-los em consideração.

\section{Referências bibliográficas}

BENTO, Jorge, Desporto para crianças e jovens: das causas e dos fins. In Adroaldo GAIA, António MARQUES e Go TANI (Orgs.), Desporto para crianças e jovens. Razóes e finalidades (pp. 21-56). Porto Alegre, Editora UFRGS, 2004.

GOMES, Paula Botelho, SILVA, Paula, QUEIRÓS, Paula, Equidade na educą̧ão: educaçăo fisica e desporto na escola. Lisboa, Associaçăo Portuguesa Mulher e Desporto, 2000.

CAETANO, Sílvia, Representaçōes de género e de etnia. Estudo realizado em manuais de educa̧̧āo física do $3 .^{\circ}$ ciclo do ensino básico. Dissertaçāo de mestrado, Universidade do Porto, FCDEF, 2005.

CALADO, Isabel, A utilizaçāo educativa das imagens. Porto, Porto Editora, 1994.

CLARKE, Gill, Difference matters: sexuality and physical education. In D. Penney (Ed.), Gender and physical education. Contemporary issues and future directions (pp. 41-56), London and New York, Routledge, 2001.

FERRAZ, M. a Goreti, Questôes de género na aula de educação fisica. Dissertação de mestrado, Universidade do Porto, FCDEF, 2002.

JUNQUEIRA, Rogério, $O$ reconhecimento da diversidade sexual e a problematização da homofobia no contexto escolar. In RIBEIRO, P; SILVA, M.; SOUZA, N.; GOELLNER, S.; SOUZA, J. (Org.), Corpo, género e sexualidades: discutindo práticas educativas (59-69). "Brasil, Rio Grande, Editora da FURG, 2007.

LIMA, Isabel, CHAVES, José, Imagem: os caminhos que se bifurcam. In P. DIAS, C. FREITAS (Ed), Desafios 2001, Actas da II Conferência Internacional de Informaçăo e Comunicaçāo na Educação (pp. 905-917). Braga, Universidade do Minho, 2001.

MARQUES, Margarida, MARTINS, Joana, Jovens, migrantes e a sociedade da informaşão e do conbecimento: a escola perante a diversidade. ACIME, Observatório da Imigração, 16, 2005. [em linha], disponível em: [http://www.oi.acime.gov.pt/docs/Estudos\%20OI/Estudo_OI_16.pdf], consultado em 20 Janeiro 2007.

QUEIROS, Telma, [Des] Igualdades de oportunidades nos manuais escolares de educaçāo fisica do $2 .^{\circ}$ ciclo do ensino básico? Análise das ilustraçóes $e$ das percep̧̧ōes de professores/as estagiários/as. Dissertação de mestrado, Universidade do Porto, FCDEF, 2004. 
ROQUE, Sílvia, Género e educação para o desenvolvimento, 2004, [em linha], disponível em: http://www.ces.uc.pt/nucleos/nep/documentos/genero educacaodesenvolvimento.pdf, consultado em Acesso 28 Maio 2007.

SILVA, Paula, $A$ Construçāo lestruturą̧ăo do género na aula de educą̧äo fisica no ensino secundário. Tese de doutoramento, Universidade do Porto, FCDEF, 2005.

SILVA, Paula; BOTELHO Gomes, Paula; QUEIROS, Paula, As actividades físicas e desportivas têm sexo? O género no desporto. SPEF, 28/29, 2004, pp. 53-63.

STAINBACK, Susan; STAINBACK, Willian, Aulas inclusivas. Un nuevo modo de enfocar y vivir el currículo. Madrid, Narcea Ediciones (2.a Ed), 2001.

THOMPSON, Shone, Challenging the hegemony. New Zealand women's opposition to rugby and reproduction of a capitalist patriarchy. In BIRREL, S; COLE, C.; (Eds.), Women, Sport and Culture (213-220). London, Human Kinetics, 1994.

WHEATLEY, Elisabeth, Subculturals subversions: comparing discourses on sexuality in men's and women's rugby song. In BIRREL, S; COLE, C.; (Eds.), Women, Sport and Culture (193-210). London, Human Kinetics, 1994. 